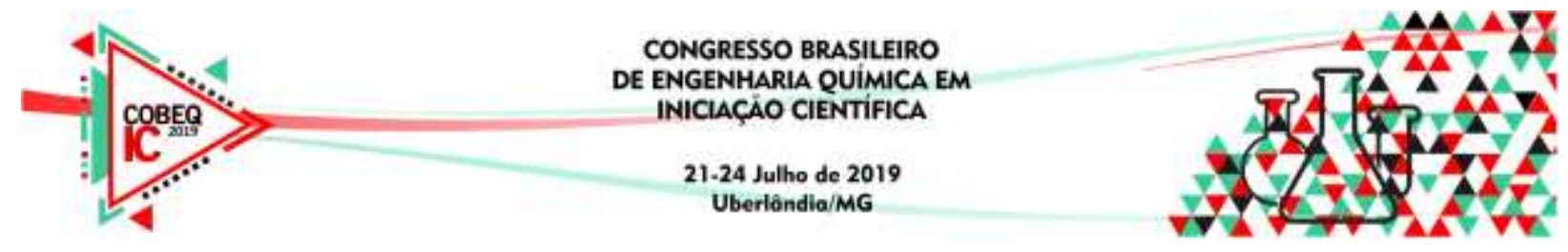

\title{
APLICAÇÃO DO AÇO AISI 316 EM TITULAÇÕES POTENCIOMÉTRICAS COMO ELETRODO INDICADOR.
}

\author{
M. F. S. MENEZES ${ }^{1}$, V. GALVES ${ }^{2}$ e M. M. P. SILVA* \\ ${ }^{1}$ Faculdade São Bernardo do Campo, Departamento de Química \\ ${ }^{2}$ Faculdade São Bernardo do Campo, Departamento de Engenharia Química \\ *E-mail para contato: mauricio.marques@ fasb.com.br
}

\begin{abstract}
RESUMO - Titulação potenciométrica é uma técnica eletroanalítica utilizada para determinar as concentrações de soluções baseando-se em potenciais medidos. Desta forma, este trabalho tem como objetivo verificar a possível utilização do aço inoxidável AISI 316 como eletrodo indicador em titulações potenciométricas de ácidos fortes e fracos por base forte, tendo como referência o eletrodo de calomelano saturado. Avaliando-se a influência da passivação com ácido nítrico nos resultados finais obtidos e comparando com resultados de titulação com pHmetro, verificou-se a equivalência do ponto estequiométrico. Os resultados obtidos mostraram que o aço AISI 316 pode ser utilizado como eletrodo indicador nos sistemas propostos.
\end{abstract}

\section{INTRODUÇÃO}

Há anos cientistas estudam a substituição de metais inertes, como a prata (Ag) e a platina (Pt), por aços inoxidáveis em análises eletroquímicas, em busca de resultados confiáveis sem elevação no custo-benefício. Por este motivo, estudos relacionados a eletrodos de menor custo se tornaram cada vez mais comuns. Atualmente, classificam-se os eletrodos em dois grandes grupos: Eletrodos de referência, que não mudam seu potencial medido, como por exemplo, o eletrodo de hidrogênio, o eletrodo de calomelano e o de prata; Eletrodos indicadores, que possuem variação no potencial de acordo com a variação da concentração do meio em que estão inseridos (HARRIS, 2011). Os eletrodos podem ser aplicados em análises como titulações potenciométricas, que se baseiam na leitura do eletrodo indicador em relação ao eletrodo de referência, conforme é realizada a variação do volume do titulante. Nas proximidades do ponto de equivalência, os potenciais sofrem variação rapidamente. (HIGSON, 2009).

Estudos sugerem aços inoxidáveis como eletrodos indicadores uma vez que permitem determinar o ponto estequiométrico de uma titulação a partir da variação do potencial medido (TERRA et al 2003). RIZZINI et al (2017) mostraram, por titulação potenciométrica, o emprego do aço AISI 430. Estes eletrodos podem ser quimicamente modificados por métodos como a passivação, que consiste na formação de um filme de óxido sobre o material, reduzindo a susceptibilidade do mesmo à corrosão (GENTIL, 2011). FREITAS et al (2017) concluíram que aço AISI 316-L apresentou bons resultados contra corrosão quando passivado em ácido nítrico $40 \%$ (v/v) em temperaturas ambientes, sendo essa passivação definida por normas técnicas (ASTM A967). 


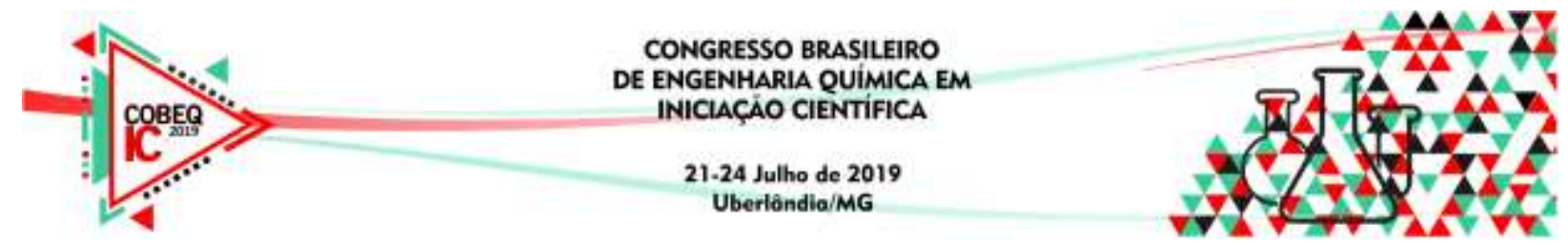

Este trabalho tem como objetivo verificar a possibilidade de utilizar o aço inoxidável AISI 316 como eletrodo indicador em titulações potenciométricas de ácidos monopróticos ( $\mathrm{HCl})$ e polipróticos $\left(\mathrm{H}_{2} \mathrm{SO}_{4} \mathrm{e} \mathrm{H}_{3} \mathrm{PO}_{4}\right)$ por base forte $(\mathrm{NaOH})$, utilizando como referência o eletrodo de calomelano saturado (ECS). Avaliando-se os resultados obtidos com placas passivadas com $\mathrm{HNO}_{3} 40 \%$ (v/v), verificou-se a equidade com volumes estequiométricos obtidos pelo método de titulação com pHmetro para sistemas com ácidos polipróticos como titulado.

\section{METODOLOGIA}

Para as determinações de potenciais as placas de aço AISI 316, de aproximadamente 7,5 x 1,2 x $0,1 \mathrm{~cm}$, foram preparadas inicialmente por meio do uso de lixas de 320, 400 e 600 mesh, sucessivamente. Após a etapa de lixamento, foi realizada a limpeza com água destilada, seguida de secagem com ar quente. Em caráter comparativo, os testes se distinguiram por placas apenas lixadas e placas submetidas a tratamento químico em banho passivante com $\mathrm{HNO}_{3} 40 \%$ (v/v) por 30 minutos em temperatura ambiente. A área de contato da placa para exposição contínua e controlada foi delimitada por meio do uso de filme transparente autoadesivo, para se evitar variações nos potenciais medidos devido à variação da área de contato com aumento do volume. Utilizaram-se para titulação soluções de $\mathrm{HCl} 0,1$ mol.L $\mathrm{L}^{-1}$, $\mathrm{H}_{2} \mathrm{SO}_{4}$ 0,05 mol.L $\mathrm{L}^{-1}, \mathrm{H}_{3} \mathrm{PO}_{4}$ 0,3 mol.L $\mathrm{L}^{-1}$ e NaOH 0,1 mol.L $\mathrm{L}^{-1}$, NaOH 0,3 mol.L $\mathrm{L}^{-1}$, sendo $\mathrm{NaOH}$ o titulante e $\mathrm{HCl}, \mathrm{H}_{2} \mathrm{SO}_{4} \mathrm{e} \mathrm{H}_{3} \mathrm{PO}_{4}$ os titulados . As placas foram submetidas à estabilização na solução do titulado por 20 minutos. Durante a titulação, foram registrados os volumes do titulante e potenciais medidos em $\mathrm{mV}$, utilizando o ECS como referência, com tempo de estabilização de um minuto entre cada medida, variando-se o volume de 0,5 em 0,5 mL. A verificação do ponto estequiométrico como contraprova foi realizada a partir da titulação com pHmetro para facilitar a visualização da inflexão dos múltiplos pontos de equivalência. Todos os ensaios foram realizados à temperatura ambiente de $25^{\circ} \mathrm{C}$, com duas placas, e em duplicatas em dias diferentes, garantindo-se assim a reprodutibilidade do experimento.

\section{RESULTADOS E DISCUSSÕES}

\subsection{Tabela}

A Tabela 1 apresenta os resultados obtidos para o ponto estequiométrico através da titulação potenciométrica. Os potenciais foram medidos em $\mathrm{mV} / \mathrm{ECS}$ e registrados para obtenção da curva da titulação em função do volume de titulante adicionado à solução, a partir da qual construiu-se a curva da $1^{\circ}$ derivada, sabendo-se que o ponto de máximo ou de mínimo da derivada corresponde ao volume de titulante adicionado para obtenção do ponto estequiométrico da titulação.

De modo geral, é possível observar que os volumes de titulante para atingir o ponto estequiométrico nas titulações utilizando o aço AISI 316 são muito próximos aos obtidos pelo método convencional utilizando o pHmetro, tendo apenas alguns desvios nas repetições.

Nas titulações com ácido clorídrico $(\mathrm{HCl})$, tanto os resultados com a placa sem passivação como os resultados da mesma com passivação são valores próximos. Nas titulações com ácido sulfúrico $\left(\mathrm{H}_{2} \mathrm{SO}_{4}\right)$ é possível verificar uma diferença de valor maior entre 

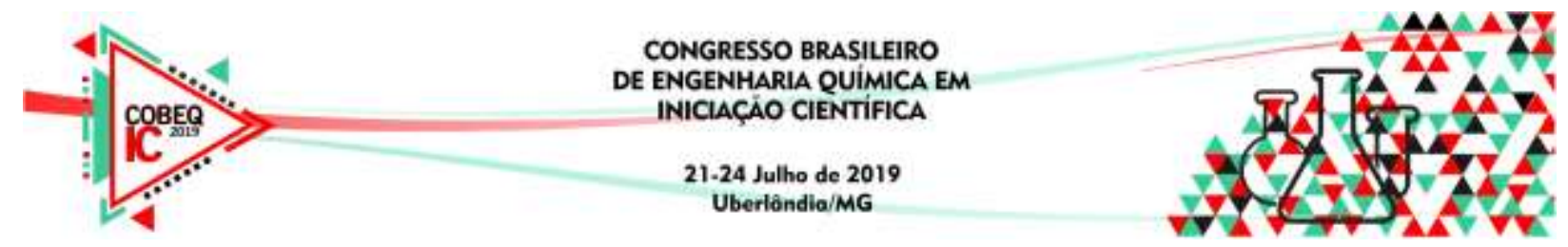

as placas passivada e sem passivação, indicando assim um melhor resultado em placas submetidas a tratamento químico. Os resultados das análises com ácido fosfórico $\left(\mathrm{H}_{3} \mathrm{PO}_{4}\right)$ deixa evidente a importância da passivação, reduzindo a susceptibilidade do aço inoxidável à corrosão, logo, gerando melhores resultados.

Tabela 1: Volume de hidróxido de sódio gasto para a neutralização dos ácidos utilizando pHmetro e ensaio potenciométrico

\begin{tabular}{|l|c|c|c|c|c|c|}
\hline & \multicolumn{5}{|c|}{ Volume de $\mathrm{NaOH}$ para o Ponto Estequiométrico (mL). } \\
\hline Ácidos & $\mathrm{HCl}$ & $\begin{array}{l}\mathrm{HCl} \text { c/ } \\
\text { passivação }\end{array}$ & $\mathrm{H}_{2} \mathrm{SO}_{4}$ & $\begin{array}{l}\mathrm{H}_{2} \mathrm{SO}_{4} \mathrm{c} / \\
\text { passivação }\end{array}$ & $\mathrm{H}_{3} \mathrm{PO}_{4}$ & $\begin{array}{l}\mathrm{H}_{3} \mathrm{PO}_{4} \mathrm{c} / \\
\text { passivação }\end{array}$ \\
\hline pHmetro & 6,0 & 5,5 & 6,0 & 5,0 & $2,0 / 3,5$ & $2,0 / 3,5$ \\
\hline Ensaio & 6,1 & 5,2 & 5,4 & 4,9 & $1,5 / 3,0$ & $1,7 / 3,3$ \\
\hline
\end{tabular}

\subsection{Figuras}

As figuras a seguir apresentam as curvas de titulações obtidas em todos os experimentos realizados com os ácidos citados anteriormente.

As Figuras 1 e 2 mostram resultados obtidos a partir de titulações de ácido clorídrico (HCl) com placas do aço AISI 316 sem passivação. Na Figura 2, é possível verificar instabilidade nos potenciais antes do ponto estequiométrico, porém sem prejudicar a visualização do mesmo. As Figuras 3 e 4 mostram os mesmos resultados, mas com placas do aço AISI 316 submetidas a tratamento químico.

Figura 1: Titulação de hidróxido de sódio 0,1 mol.L ${ }^{-1}$ (titulante) e ácido clorídrico 0,1 mol.L -1 $^{-1}$ titulado). Placa sem passivação.

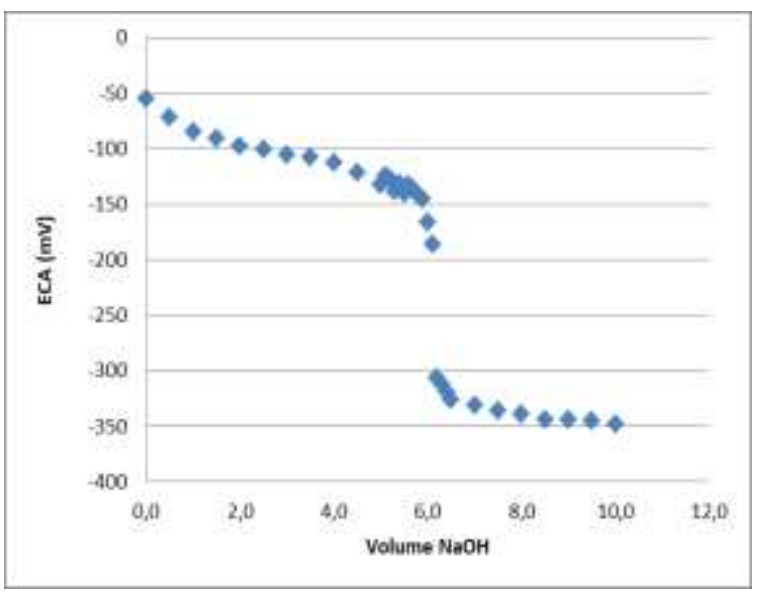

Figura 2: Titulação de hidróxido de sódio 0,1 mol.L ${ }^{-1}$ (titulante) e ácido clorídrico 0,1 mol.L ${ }^{-1}$ (titulado). Placa sem passivação. Gráfico da $1^{\mathrm{a}}$ derivada.

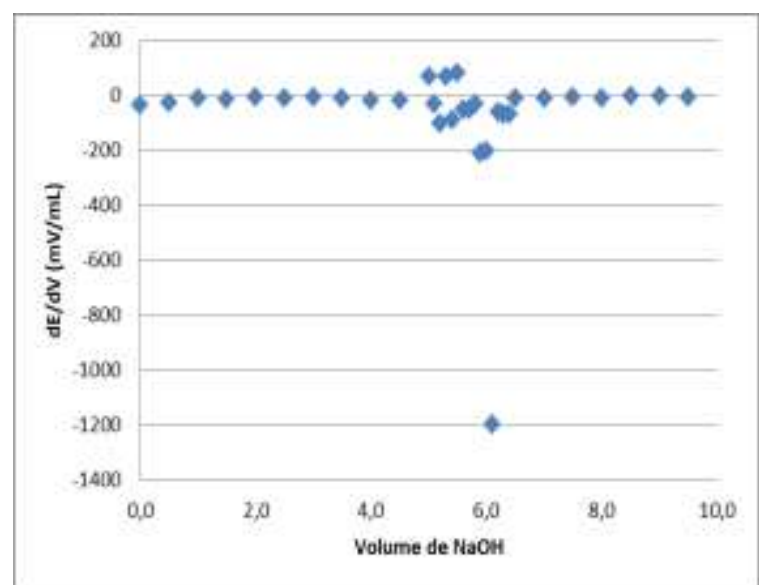


Figura 3: Titulação de hidróxido de sódio 0,1 mol. $\mathrm{L}^{-1}$ (titulante) e ácido clorídrico 0,1 mol.L $\mathrm{L}^{-1}$ (titulado). Aço 316 passivado.

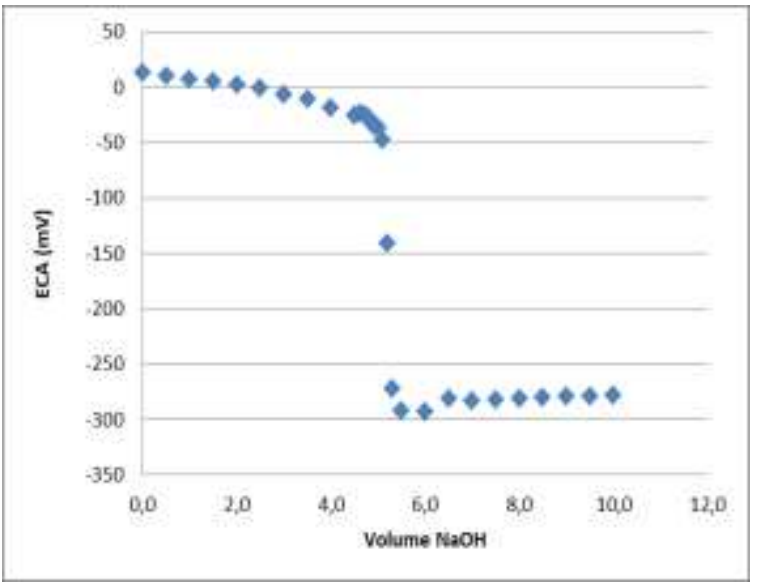

Figura 4: Titulação de hidróxido de sódio (titulante) e ácido clorídrico (titulado). Placa passivada - Gráfico da $1^{\text {a }}$ derivada.

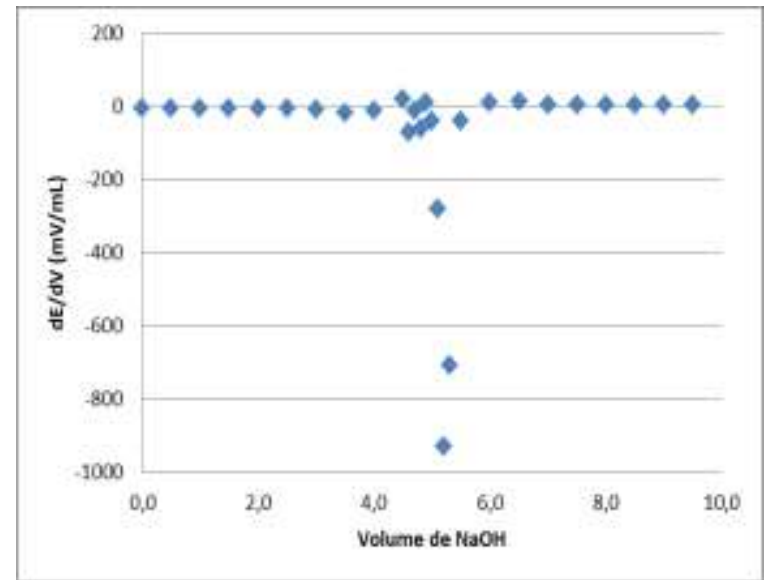

As Figuras 5 e 6 apresentam os resultados de curvas de titulação realizadas com o ácido sulfúrico, sem passivação prévia do aço 316. Nesse ensaio, o ponto estequiométrico variou razoavelmente em relação à titulação feita somente com o pHmetro, sendo assim, os resultados apresentam uma pequena instabilidade que pode ter ocorrido por uma possível corrosão do aço. As Figuras 7 e 8 mostram os mesmos resultados, porém com placas passivadas.

Figura 5: Titulação de hidróxido de sódio 0,1 mol. $\mathrm{L}^{-1}$ (titulante) e ácido sulfúrico 0,05 mol. $\mathrm{L}^{-1}$ (titulado). Placa sem passivação.

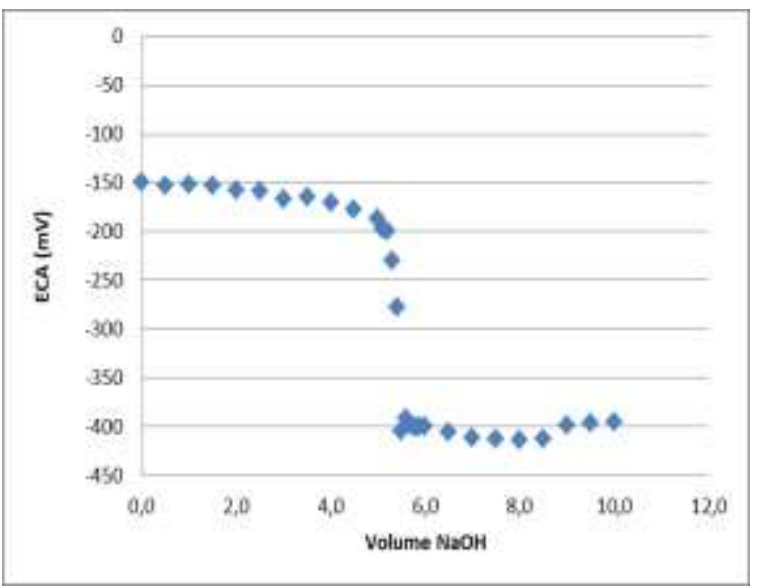

Figura 6: Titulação de hidróxido de sódio 0,1 mol.L ${ }^{-1}$ (titulante) e ácido sulfúrico 0,05 mol. $\mathrm{L}^{-1}$ (titulado). Placa sem passivação - Gráfico da $1^{\mathrm{a}}$ derivada.

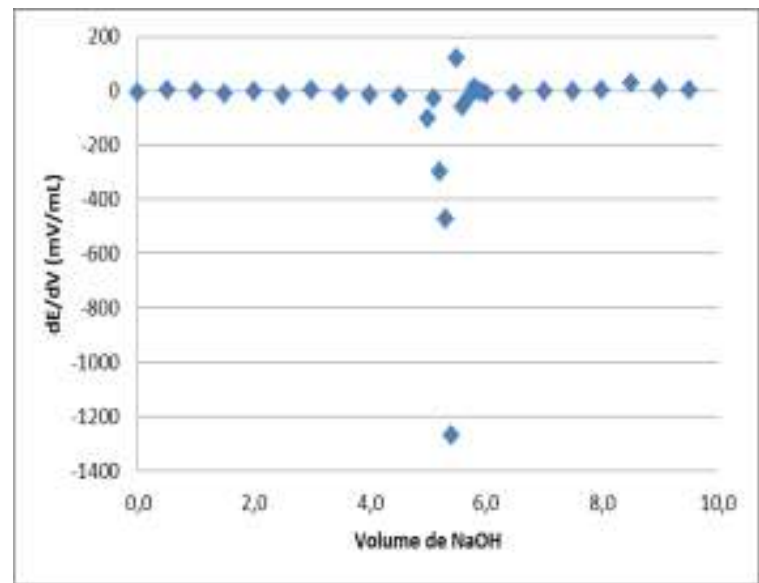




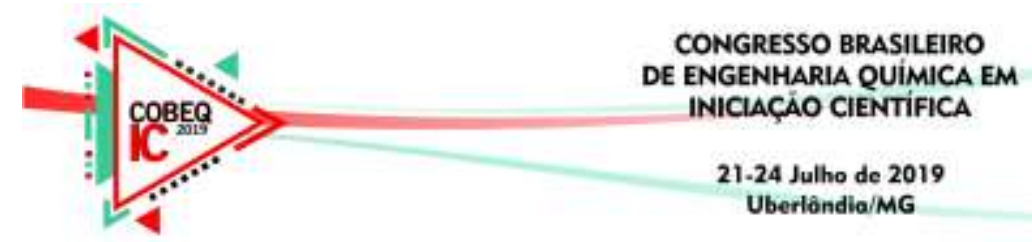

Figura 8: Titulação de hidróxido de sódio

Figura 7: Titulação de hidróxido de sódio 0,1 mol. $\mathrm{L}^{-1}$ (titulante) e ácido sulfúrico 0,05 mol. $\mathrm{L}^{-1}$ (titulado). Placa passivada.

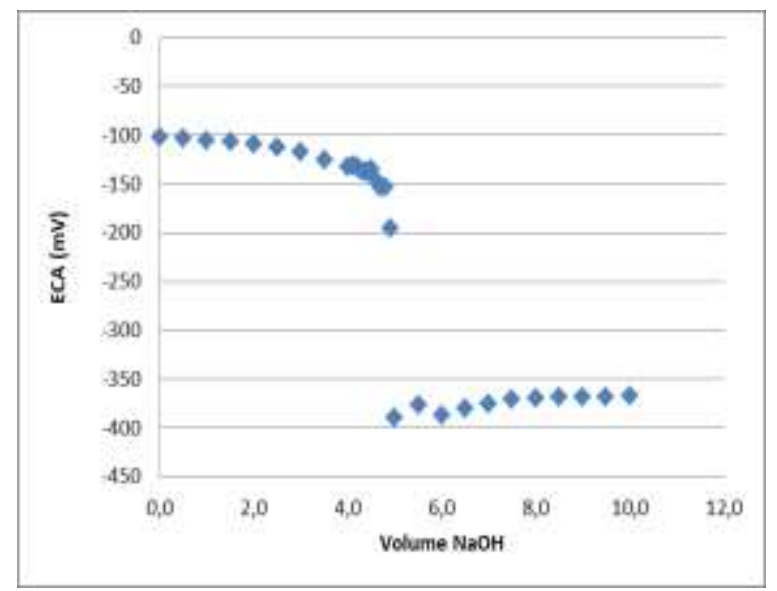
0,1 mol.L $\mathrm{L}^{-1}$ (titulante) e ácido sulfúrico 0,05 mol. $\mathrm{L}^{-1}$ (titulado). Placa passivada Gráfico da $1^{\text {a }}$ derivada.

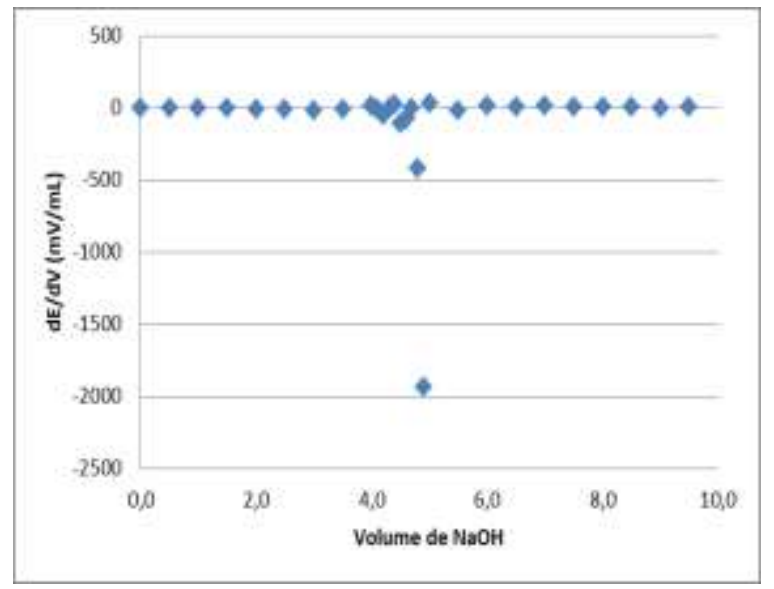

As Figuras 9 e 10 apresentam resultados obtidos a partir da titulação com ácido fosfórico $\left(\mathrm{H}_{3} \mathrm{PO}_{4}\right)$ com placas sem passivação. As Figuras 11 e 12 apresentam os mesmos resultados, porém com placas passivadas. De acordo com as análises das figuras, é possível notar instabilidade de potencial medido em placas sem passivação, o que aumenta a probabilidade de uma possível corrosão do aço. Sendo assim, o tratamento químico no aço se torna de grande importância para titulação com este ácido.

Figura 9: Titulação de hidróxido de sódio 0,3 mol. $\mathrm{L}^{-1}$ (titulante) e ácido fosfórico 0,1 mol.L $\mathrm{L}^{-1}$ (titulado). Placa sem passivação.

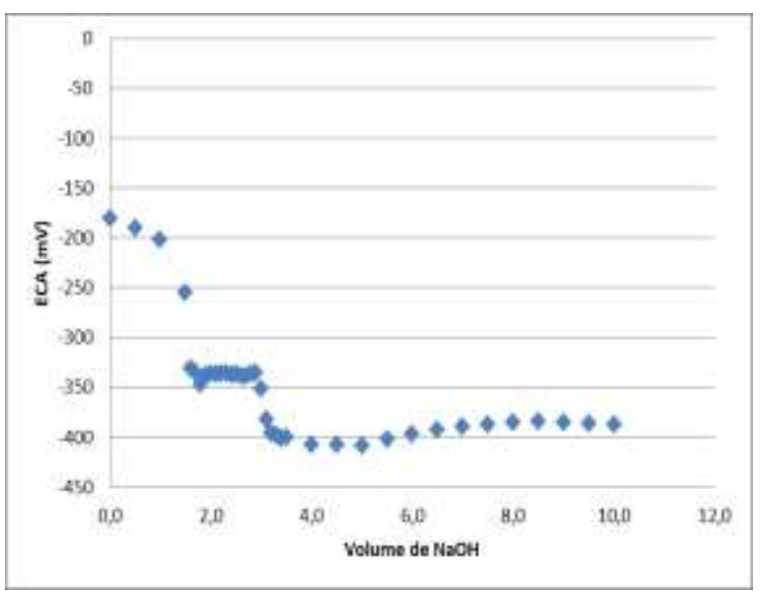

Figura 10: Titulação de hidróxido de sódio 0,3 mol. $\mathrm{L}^{-1}$ (titulante) e ácido fosfórico 0,1 mol. $L^{-1}$ (titulado). Placa sem passivação Gráfico da $1^{\mathrm{a}}$ derivada

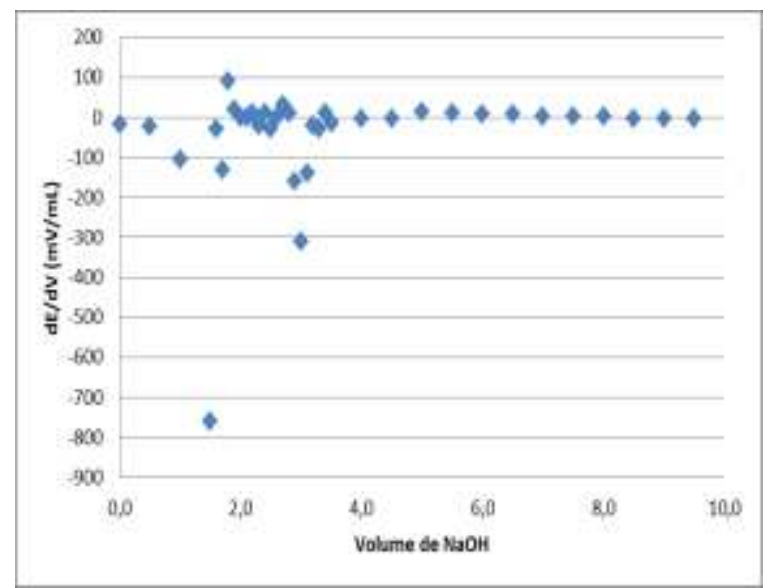




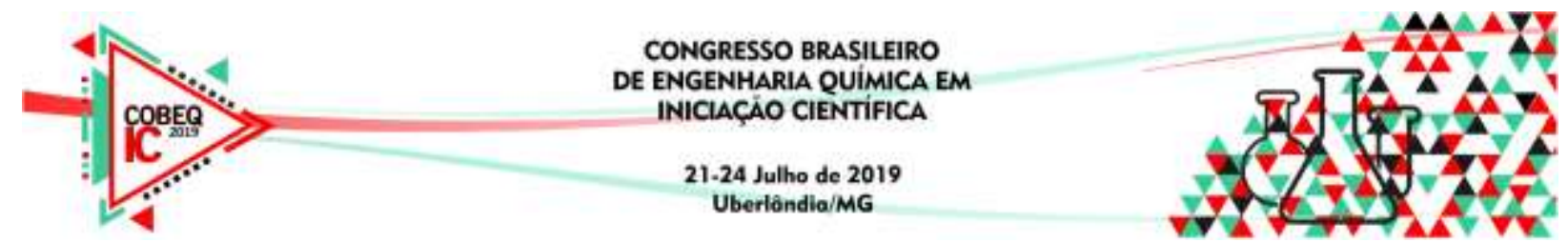

Figura 11: Titulação de hidróxido de sódio 0,3 mol. $\mathrm{L}^{-1}$ (titulante) e ácido fosfórico 0,1 mol. $L^{-1}$ (titulado).

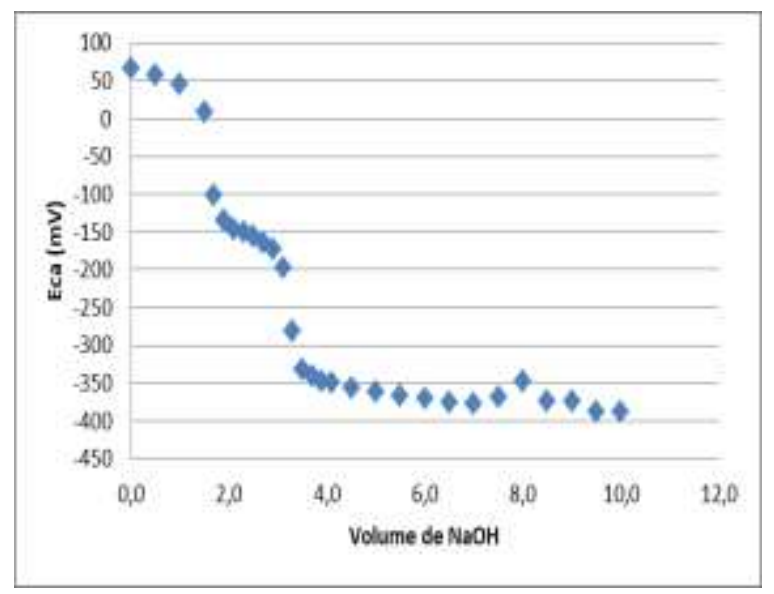

Figura 12: Titulação de hidróxido de sódio 0,3 mol. $\mathrm{L}^{-1}$ (titulante) e ácido fosfórico 0,1 mol. $\mathrm{L}^{-1}$ (titulado). Placa passivada Gráfico da $1^{\text {a }}$ derivada.

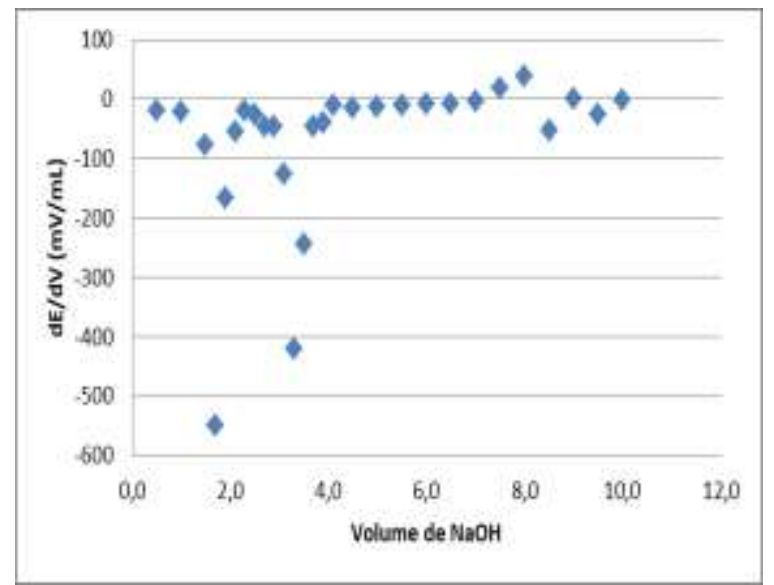

\section{CONCLUSÕES}

Após a análise dos gráficos apresentados, é possível concluir que o aço inoxidável AISI 316 pode ser utilizado em titulações potenciométricas de ácido clorídrico e hidróxido de sódio, uma vez que os volumes estequiométricos obtidos se aproximam aos do método de titulação tradicional, assim como a curva de titulação. Em análises de titulação potenciométrica com ácido sulfúrico e ácido fosfórico, recomenda-se o tratamento químico do aço por passivação, a fim de evitar corrosão prévia das placas de aço AISI 316 e interferências nos resultados.

\section{REFERÊNCIAS BIBLIOGRÁFICAS}

AMERICAN SOCIETY FOR TESTING AND MATERIALS. A967 / A967M-13: Standard Specification for Chemical Passivation Treatments for Stainless Steel Parts. West Conshohocken, 2007.

GENTIL, Vicente. Corrosão. LTC, Rio de Janeiro, 6ª edição, 2011.

HARRIS, Daniel. Explorando a química analítica. Ed. 4. Rio de Janeiro: Editora LTC, 2011. $550 \mathrm{p}$.

HIGSON, Seamus. Química analítica. Ed. 1. São Paulo: Editora McGraw-Hill, 2009. 452 p.

RIZZINI, Priscila Figlioli; et al. Aplicação do Aço AISI 430 como eletrodo indicador em titulação potênciométrica. In: 12a COBEQ, 2017.

TERRA, Lucia Helena; et al. Construção e Aplicação de Eletrodo de Aço Inoxidável UNS S31254 Como Eletrodo Indicador em Titulações Condutimétricas. Química Nova. São Paulo, n. 1, v. 26, p. 21-24, 2003.

V.V. FREITAS, K. J. B. ALVES, M. F. ROMEU. Estudo comparativo da passivação do aço 316-L com ácido nítrico e ácido sulfúrico em diferentes temperaturas. In: $12^{\mathrm{a}} \mathrm{COBEQ}$, 2017. 